\title{
Underwater Visual Records of Marine Megafauna Around Offshore Anthropogenic Structures
}

\author{
Victoria L. G. Todd ${ }^{1,2 *}$, Laura Lazar', Laura D. Williamson ${ }^{1,2}$, Ingrid T. Peters ${ }^{1}$, \\ Aimee L. Hoover ${ }^{1}$, Sophie E. Cox ${ }^{1}$, Ian. B. Todd ${ }^{1}$, Peter I. Macreadie ${ }^{3}$ and \\ Dianne L. McLean ${ }^{4 *}$
}

\begin{abstract}
${ }^{1}$ Ocean Science Consulting Ltd., Dunbar, United Kingdom, ${ }^{2}$ Environmental Research Institute, University of the Highlands and Islands, Thurso, United Kingdom, ${ }^{3}$ Centre for Integrative Ecology, School of Life and Environmental Sciences, Deakin University, Burwood, VIC, Australia, ${ }^{4}$ Australian Institute of Marine Science, Indian Ocean Marine Research Centre, Crawley, WA, Australia
\end{abstract}

\section{OPEN ACCESS}

Edited by:

Xavier Pochon,

Cawthron Institute, New Zealand

Reviewed by:

Janne Haugen,

University of Massachusetts Dartmouth, United States

Deanna Marie Clement, Cawthron Institute, New Zealand

*Correspondence:

Victoria L. G. Todd

vt@osc.co.uk

Dianne L. McLean

d.mclean@aims.gov.au

Specialty section: This article was submitted to Marine Ecosystem Ecology, a section of the journal Frontiers in Marine Science

Received: 08 November 2019 Accepted: 25 March 2020 Published: 21 April 2020

Citation: Todd VLG, Lazar L, Williamson LD, Peters IT, Hoover AL,

Cox SE, Todd IB, Macreadie PI and McLean DL (2020) Underwater Visual Records of Marine Megafauna Around Offshore Anthropogenic Structures. Front. Mar. Sci. 7:230 doi: 10.3389/fmars.2020.00230
In oceans and seas worldwide, an increasing number of end-of-life anthropogenic offshore structures (e.g., platforms, pipelines, manifolds, windfarms, etc.) are facing full or partial removal. As part of the decommissioning process, studies on potential importance of subsea infrastructure to marine megafauna (defined as: cetaceans, pinnipeds, sirenians, large fish - such as sharks, rays, billfishes, and tuna, as well as marine reptiles, and seabirds) are lacking. Dedicated scientific Remotely Operated Vehicle (ROV) surveys around offshore installations are rare, but there is a wealth of archived industrial data and noteworthy species sightings posted publicly on various social media platforms. This study used routine, incidentally collected ROV ( $n=73)$ and commercial diver $(n=9)$ video recordings spanning 1998-2019 globally. Data were gathered directly from industrial partners $(n=36)$ and the public domain (YouTube; $n=46$ ) to provide an account of marine megafauna presence and potential feeding behavior in the near-visible vicinity of subsea anthropogenic structures. A total of 79 video clips and 3 still images of marine megafauna near offshore structures were examined, resulting in 67 individual sightings and 16 sub-sightings (in which an individual was recorded within the same day). At least 178 individuals were identified to a minimum of 17 species of marine megafauna, amounting to a total (combined) sighting duration of 01:09:35 (hh:mm:ss). Results demonstrated proximate presence of marine megafauna (many of which are threatened species) to anthropogenic structures, with most animals displaying foraging or interaction behaviors with the structures. Observations included the deepest $(2,779 \mathrm{~m})$ confirmed record of a sleeper shark (Somniosus spp.) and the first confirmed visual evidence of seals following pipelines. These ROV observations demonstrate a latent source of easily accessible information that can expand understanding of marine megafauna interactions with offshore anthropogenic infrastructure. Consequently, other workers in this field should be encouraged to re-analyze archived datasets, commence further collaborative research projects with industrial partners, and/or expand Internet search terms to additional species assemblages, in a bid to quantitatively elucidate relationships between offshore infrastructure and marine species.

Keywords: marine megafauna, Remotely Operated Vehicle (ROV), Oil \& Gas (O\&G), mammal, shark, platform, pipeline 


\section{INTRODUCTION}

Since the industrial revolution, many species have been struggling to cope with habitat modifications, climate change, and other detrimental anthropogenic pressures (e.g., Cheung et al., 2009; Dirzo et al., 2014; IPBES, 2019). Despite increasing interest in the renewables sector, enduring investment in Oil \& Gas (O\&G) Exploration and Production to satisfy global demand has resulted in the ongoing operation of thousands of offshore structures and the continued establishment of new infrastructure in the marine environment (e.g., Todd et al., 2019). Of these, 7,500 marine offshore $\mathrm{O} \& \mathrm{G}$ installations across jurisdictions of 53 countries are expected to become obsolete in the near future (Parente et al., 2006; Fowler et al., 2018). Windfarm decommissioning is also on the horizon, but as a comparably newer industry, is less impending (Topham and McMillan, 2017).

Subsea-anthropogenic infrastructure provides structurally complex hard substrata on an often otherwise featureless sedimentary seafloor (Larcom et al., 2014). These structures can accommodate diverse sessile-invertebrate communities comprising anemones, hydroids, bryozoans, sponges, mussels, barnacles, soft, and even hard corals that can attract motile invertebrates (Guerin, 2009; Langhamer and Wilhelmsson, 2009; McLean et al., 2017; Meyer et al., 2018; Todd et al., 2018, 2019). With time, subsea structures encourage benthic complexity, which supports fish populations through a strong foraging base (Cowan and Rose, 2016), increasing trophic-level ecological succession. Consequently, anthropogenic infrastructure has large-scale positive and negative social, economic, and ecological impacts. These structures sustain trophic connectivity through nutrient and resource flow, pelagic-larval dispersal, pipeline linkage, and movement of mobile predators (Macreadie et al., 2011; Henry et al., 2018; van der Molen et al., 2018).

A total of $14.7 \%$ of the North Sea has been designated as Marine Protected Areas, MPAs (OSPAR, 2017), and an additional $0.1 \%$ comprises the 500 - $\mathrm{m}$ shipping (including fishing) exclusion zones of offshore O\&G structures (UK Public General Acts, 1987; UK National Data Repository, 2019). This safety exclusion zone is reduced to $50 \mathrm{~m}$ around windfarm turbine bases, and only increases to $500 \mathrm{~m}$ around renewable construction sites (FLOWW, 2014). Some offshore installations could potentially be acting as mini MPAs, which has galvanized a number of both academic and industry scientists to jointly investigate possibility that there may be positive environmental outcomes of industrial usage of the marine environment. Consequently, this has sparked debate about whether to leave some, well-placed offshore structures, particularly O\&G platforms, in situ as artificial Rigsto-Reefs, RTR (Kaiser and Pulsipher, 2005) or remove them completely from the seabed. Removal of infrastructure at the end of its field life is legislated currently in Europe under the Oslo and Paris Convention (OSPAR) Decision 98/3, on the Disposal of Disused Offshore Installations (OSPAR, 1998).

In the North Sea, there is likely a high level of ecological interconnectedness between the network of local ecosystems comprising 1,350 offshore O\&G installations, including 545 fixed steel platforms, 81 offshore windfarms with 3,589 turbines (North SEE, 2016), and a plethora of wrecks (Coolen and Jak, 2018).
There is no doubt that increasing numbers of artificial structures in the marine environment - adversely termed 'ocean sprawl' by Bishop et al. (2017) - modifies the local marine ecosystem. In a similar vein, commercial fishing (especially dredging and trawling) has also altered large tranches of the ocean seabed beyond recognition. Re-conversion to the original ecosystem is unlikely to be achievable in the long term, as the North Sea continues to be exploited by industrial stakeholders.

The RTR concept began as early as 1975, when in the South China Sea (Malaysia) the storm-damaged Baram- 8 platform was toppled to form the base of an artificial reef (Zawawi et al., 2012). Since then, RTR schemes have been legislated only in Brunei's sector of the South China Sea (Twomey, 2012), and in the United States' (US) Gulf of Mexico (GoM) in Louisiana and Texas, and in Pacific California (Jørgensen, 2009). Successful RTR implementation, however, has occurred only in Brunei and the GoM, despite increasing support from both academic and industry scientists, for the concept of leaving well-studied and potentially environmentally beneficial offshore structures in situ at the end of operational lifetimes (Jørgensen, 2012; Macreadie et al., 2012; McLean et al., 2017; Fowler et al., 2018; Todd et al., 2018, 2019; van Elden et al., 2019).

To determine environmental impacts of future decommissioning projects on a case-by-case basis, it is important to consider potential interactions between prey species congregating around structures with organisms at higher trophic levels. For example, because of the general tendency of any object placed in the water to attract fish and other marine life, marine megafauna, such as mammals, large fish (including sharks), reptiles and seabirds, might be attracted to these locations for temporo-spatially predictable foraging opportunities (McClellan et al., 2014; McLean et al., 2019b).

To date, only a handful of studies have been conducted on marine mammal interactions with offshore anthropogenic infrastructure, mostly in the North Sea. The first acoustic study was carried out in the German North Sea by Todd et al. (2009) using analog autonomous underwater passive cetacean echolocation-click detectors (T-PODs) deployed directly from an offshore O\&G exploration jack-up drilling rig at an established production platform. Harbor porpoises (Phocoena phocoena) were detected, predominantly at night, in very close proximity $(<300 \mathrm{~m})$ to installations with a pronounced diel pattern (Todd et al., 2009). Another North and Irish Sea acoustic and visual study on various offshore $O \& G$ installations, reported multiple marine mammal species, including harbor porpoise, Atlantic white-sided (Lagenorhynchus acutus), white-beaked (Lagenorhynchus albirostris), and common (Delphinus delphis) dolphin, minke whale (Balaenoptera acutorostrata), and both common (Phoca vitulina) and gray (Halichoerus grypus) seal (Todd et al., 2016). Similarly, Delefosse et al. (2018) analyzed visual sightings from 25 O\&G installations in the Dutch sector of the North Sea, recording 131 sightings of 288 individual marine mammals over a 3-year period. Harbor porpoise was the most commonly sighted species (41\% of sightings), followed by minke whale (31\%). Regarding offshore renewables, Russell et al. (2014) observed tagged common and gray seal targeting windfarm turbine piles, presumably to feed. In other oceans 
worldwide, a visual study in the Adriatic sea reported bottlenose dolphin (Tursiops truncatus) within $750 \mathrm{~m}$ of O\&G platforms (Triossi et al., 2013), and in the Pacific USA, California sea lion (Zalophus californianus) were found to haul out and nurse young regularly on O\&G installations (Orr et al., 2017). In Australia, Arnould et al. (2015) reported that 25\% of 36 tagged Australian fur seals (Arctocephalus pusillus) exhibited foraging behavior near offshore anthropogenic structures, potentially targeting areas around $\mathrm{O} \& \mathrm{G}$ pipelines and cable routes.

Little information is available on associations of elasmobranchs (cartilaginous fish, such as sharks) with anthropogenic structures. In the North Sea, a basking shark has been sighted within the 500-m zone of an offshore installation (Todd et al., 2016). Whale sharks (Rhincodon typus) aggregate in high densities around offshore Arabian Gulf O\&G platforms (Robinson et al., 2013). Four whale sharks were observed at a platform in Australia (McLean et al., 2019a). ROV imagery of wells in Australia has also led to observations of a gray nurse shark (Carcharias taurus), spinner shark (Carcharhinus brevipinna), ribbontail ray (Taeniura meyeni), and speckled swellsharks, Cephaloscyllium speccum (McLean et al., 2018b). Most investigations have focussed on impacts of Electro-Magnetic Fields (EMFs), since sharks can sense very weak, bioelectric fields to detect prey (Kalmijn, 1982; Walker et al., 1992; Kajiura and Holland, 2002; Kajiura, 2003), predators (Sisneros et al., 1998; Kempster et al., 2013), mates (Tricas et al., 1995; Sisneros and Tricas, 2002), and potentially navigate on large global scales (Klimley, 1993; Klimley et al., 2002; Meyer et al., 2005). Consequently, interactions with anthropogenic structures are likely commonplace, but underreported.

Studies of large bony fish species that can grow to $2 \mathrm{~m}$ or bigger near offshore O\&G platforms are rare. Martin and Lowe (2010) reported 53 fish species near O\&G platforms off coastal California, United States, including two sightings of the ocean sunfish (Mola mola), the largest bony fish in the world (Wood, 1983; Pan et al., 2016). Most studies have focused predominantly on commercially important fish observed in association with subsea infrastructure (Jørgensen et al., 2002; Løkkeborg et al., 2002; Soldal et al., 2002; Guerin, 2009; Friedlander et al., 2014; Fujii et al., 2014). Indeed, many of the fish in these studies were juveniles, preferentially selecting structurally complex habitats (Sayer et al., 2005).

Impacts of O\&G operations on marine reptiles (e.g., marine turtles and sea snakes) are unknown (Maxwell et al., 2019). A review of underwater sightings in the GoM found that marine turtles were observed visiting anthropogenic structures for short periods (1-5 h), particularly at night (Rosman et al., 1987). Marine turtles have also been found to associate more frequently with smaller, unmanned platforms that are closer to shore (Lohoefener et al., 1990). A recent Australian ROV study observed a flatback turtle (Natator depressus) and an unidentified sea snake (Hydrophiidae) immediately adjacent to a pipeline (McLean et al., 2019b).

Acoustic and surface-based detections have been analyzed previously (as reviewed here); however, there are few reports of megafauna from underwater visual sources. The objective of this study was to determine feasibility of using industrysupplied or publicly sourced visual data to assess presence and behavior of marine megafauna in close vicinity to offshore anthropogenic structures. These data were collected during routine offshore $\mathrm{O} \& \mathrm{G}$ and renewable energy infrastructure ROV General Visual Inspection (GVI) and commercial-diver Inspection, Maintenance and Repair (IMR) surveys. These industrial data are beginning to be used more regularly for assessments of fish and benthic species (e.g., McLean et al., 2017,2020 ), but use in investigations of megafauna presence is understudied.

\section{MATERIALS AND METHODS}

\section{Data Acquisition}

Industrial recordings of marine megafauna sightings were sourced from routine, non-scientific inspection and maintenance operations of subsea offshore infrastructure using inspectionclass ROVs and commercial diver video recording systems of unknown specifications. A mass data request email was sent to the contact email address (e.g., info@) of >50 companies in these sectors, outlining purpose of the research, a re-assurance of data confidentiality, and an invitation to submit marine megafauna imagery of interest. Marine megafauna were defined as: cetaceans, pinnipeds, sirenians, large fish (species known to exceed $2 \mathrm{~m}$ ), such as sharks, rays, billfishes and tuna, as well as marine reptiles, such as marine turtles, sea snakes, and, seabirds (adapted from McClellan et al., 2014). Imagery was either provided anonymously by industry (e.g., ROV pilots) or obtained through dedicated Internet searches of public domain YouTube $e^{1}$ online archives. Use of data from Twitter and Facebook was investigated, but YouTube was found to be the richest source of data for these purposes, and was therefore the focus.

Analysis was performed between the months of February to October 2019, applying a similar methodological approach used for medical reviews (e.g., by Ache and Wallace, 2008; Duncan et al., 2013). Search strategy consisted of entering a combination of marine megafauna and anthropogenic structure search terms (Table 1), followed by either ' $R O V$ ' or 'commercial diver' into YouTube using Google Chrome (version 75.0.3770.142) or Firefox (v68.0.1). Anthropogenic terms were derived from the O\&G (Schlumberger, 2019) and Wind energy glossaries (Nordman, 2010; Wind Energy Association, 2020). These term combinations were used to search iteratively, e.g., 'Aquatic mammal blowout preventer ROV', followed by 'Aquatic mammal blowout preventer commercial diver,' then 'big fish blowout preventer ROV', and so on. Since there is considerable variation across industry in use/non-use of spacing between terms (e.g., spudcan vs. spud can, windfarm vs. wind farm, etc.), both were used where applicable. Moreover, since the O\&G industry (and to a lesser extent, the renewable sector) rely predominantly on acronyms, these were also applied, where appropriate. Each listed result was reviewed individually until no search terms remained in the video title. Only videos originating from an ROV camera or a commercial

\footnotetext{
${ }^{1}$ www.YouTube.com
} 
dive recording were considered. The online video converter 'YouTube Converter \& Downloader' (v3.0) was used to download and convert imagery from YouTube to Moving Pictures Expert Group (MPEG) - 4 Part 14 (.mp4) format.

\section{Imagery Processing}

Each video was quality assessed and analyzed using Windows Media Player 12 (Microsoft) or VLC media player (VideoLAN, v3.0.6). Imagery was first screened for visible presence of marine megafauna and a permanent anthropogenic structure. Videos lacking clear images, as a result of very low quality, or non-commercial imagery (e.g., recreational dive recordings), were excluded from further analysis. All available metadata (e.g., time, date, depth, coordinates, operation type, project, equipment, and structure type) were recorded. Stills of imagery were taken, with permission from industry providers, using the built-in VLC media player snapshot tool or Windows Snipping tool. Permission to present stills from YouTube videos was challenging; consequently, only Uniform Resource Locator (URL) hyperlinks to footage have been presented. Authors are not accountable for URL content and have endeavored to provide correct links; however, uploaded videos are occasionally removed or may be country-restrictive.

Audible ROV pilot/commercial diver commentaries, and annotations found in video descriptions (e.g., location) were

TABLE 1 | Internet search terms used in every possible permutation, followed by either the term 'ROV' or 'commercial diver' to source video imagery related to marine megafauna sightings from the public domain (listed alphabetically).

\begin{tabular}{|c|c|c|}
\hline \multirow{2}{*}{$\begin{array}{l}\text { Marine megafauna terms } \\
\text { Aquatic mammal }\end{array}$} & \multicolumn{2}{|c|}{ Anthropogenic structure terms } \\
\hline & Blowout preventer & Pipeline \\
\hline Big fish & $\mathrm{BOP}$ & Platform \\
\hline Cetacean & Cable & Production \\
\hline Dolphin & Caissons & Renewable \\
\hline Dugong & Conductor & Rig \\
\hline Elasmobranch & Construction & Spudcan \\
\hline Manatee & Drilling & Structure \\
\hline Marine mammal & Foundation & Subsea \\
\hline Megafauna & Gas & Tower \\
\hline Pinniped & Industry & Tripod \\
\hline Porpoise & Inspection & Turbine \\
\hline Ray & Installation & Umbilical \\
\hline Reptile & Jacket & Underwater \\
\hline Seabird & Jack-up & Valve \\
\hline Seal & Leg & Welding \\
\hline Sea lion & Manifold & Well \\
\hline Sea monster & Maritime & Wind \\
\hline Sea otter & Monopile & Windfarm \\
\hline Sea snake & $O \& G$ & Windpark \\
\hline Shark & Offshore & \\
\hline Sirenia & Oil & \\
\hline Turtle & Operation & \\
\hline Walrus & Pile & \\
\hline Whale & Piling & \\
\hline
\end{tabular}

BOP, BlowOut Preventer; O\&G, Oil \& Gas. recorded if they augmented video metadata. Geographic coordinates, including Universal Transverse Mercator (UTM) zone - or at least an approximate location - were applied to species identification (ID) analysis. The sighting map was created in QGIS v3.2.3 using WGS '84. Diel variations were not accounted for, due to varying conditions (artificial lights, depth, time zone, lack of metadata). Time-stamp format (local or in Greenwich Mean Time Zone, GMT) was not available, and hence assumed to be in local time.

Several videos were available only as truncated segments of what would have clearly been a full-length sighting. Consequently, imagery that was obviously recorded on the same day of an operation that contained multiple sightings of the same individual from the same installation (i.e., re-identified due to unique recognizable markings, such as white pigmentation on a seal) were combined as 'sub-sightings' of the same 'sighting.' Video clips taken by multiple cameras on the same ROV (duplicates), but from a different angle within a 5-s period, were noted but excluded from further analysis to avoid replication. All commercially sensitive information (such as client, vessel, project, ROV operator, etc.) sourced from videos submitted by clients under Non-Disclosure Agreement (NDA) were redacted (Figure 1).

Megafauna were categorized into groups (e.g., whale, dolphin, seal, shark, ray, fish, turtle, bird, etc.) and identified to lowest taxonomic rank using appropriate identification guides (e.g., Hvass, 1978; Compagno et al., 2004; Shirihai and Jarrett, 2006; Jefferson et al., 2015; Nelson et al., 2016). Identifying the sex of an individual was not considered a classifiable criterion, because of a high margin of error. Threat status of all identified species was sourced from the International Union for Conservation

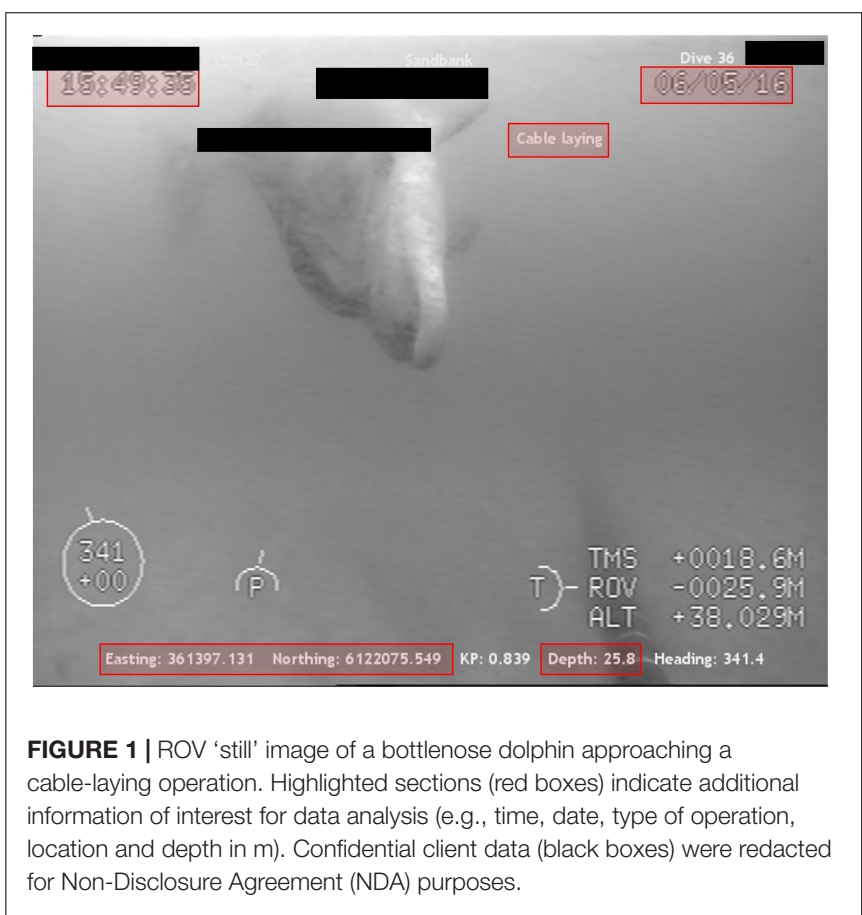


of Nature (IUCN) Red List of Threatened Species ${ }^{2}$. Additional species considered to be interacting with megafauna (e.g., prey) were also recorded and identified, where possible, as was sighting duration (time in which individual was visible on-screen). Quantification of size of individual or distance to anthropogenic structure at closest approach was not possible and was reliant on camera Field of View (FOV). Any fish species that is known to grow to $2 \mathrm{~m}$ or more was included in analysis; however, only a qualitative estimation of size (big vs. small) can be made, as morphometrics/scarring/colouration and even sex of individuals, especially fish, change visibly with age. For example, most groupers (Epinephelidae) are protogynous hermaphrodites, which means that as they age, body proportions change in appearance, and notable color fading/scarring can be visible (Zhou and Gui, 2010; Chen et al., 2019).

Imagery was grouped by distance of approach between animal and structure. Categories included 'direct' physical contact with structure, 'approaching' structure to within 1$2 \mathrm{~m}$ (based on FOV and normal size of adult animals), and 'no approach', e.g., swimming past structure in the distance. Imagery duration (effort) and sighting duration were recorded in minutes:seconds (mm:ss).

Categorization of behavioral activity was somewhat difficult to quantify for such a wide range of species; however, for certain megafauna, such as seals, and perhaps some sharks, an attempt was made to classify behavior into five categories. These were based on predominantly observed behavior, adapted from Wauters et al. (1992): searching, foraging, traveling, interaction, or other. Searching was defined as head moving up and down and/or from side to side in what was perceived as a method to identify prey. Foraging attempts were defined as individuals deviating from travel path sharply to attempt to and/or catch and feed on prey. Traveling was assigned when an individual swam in a consistent direction with no deviation associated with foraging or searching. Interaction was defined as individuals that were affected (i.e., change in behavior) through contact with anthropogenic equipment, structure, or diver. Behaviors were classified as other when they did not fall into any previous categories, e.g., no movement.

\section{RESULTS}

\section{Recording Source}

A total of $n=79$ video clips and $n=3$ still images were analyzed (total $n=82$ ) with a total effort duration of 1:46:30 hh:mm:ss. The info@ call for new industrial footage elicited zero response from industry; consequently, most videos $(n=46)$ were sourced from the public domain (YouTube), and $n=36$ were from archived or obtained directly from colleagues working in the O\&G industry. Imagery was recorded mainly by ROVs of unknown specification $(n=73)$, and a handful $(n=9)$ recorded by commercial dive cameras of unknown specification. Some video clips $(n=5)$ were collected from more than one date (e.g., a compilation of several clips). Of videos sourced from industry, $n=8$ duplicates were

${ }^{2}$ www.iucnredlist.org excluded from further analysis, resulting in a total of $n=74$ useable recordings.

Data were sourced across 21 years from May 1998 to July 2019, originating from 62 separate days. Most imagery was recorded in 2018 ( $n=17$ recordings, all in August), followed by $2006(n=10)$, and $2009(n=9)$. Imagery was collected throughout the year, with a seasonal trend toward August $(n=23)$, followed by September and October $(n=5)$ in the northern hemisphere $(n=54)$. In the southern hemisphere $(n=6)$, more data were collected in October $(n=3)$. Remaining recordings without location data $(n=22)$ were recorded equally throughout the year.

\section{Marine Megafauna Sightings}

From the $n=74$ useable recordings, $n=67$ individual marine megafauna sightings were identified (Table 2 and Supplementary Table 1) totalling 01:09:35 hh:mm:ss. Each sighting ranged from $1 \mathrm{~s}$ to $4 \mathrm{~min} 29 \mathrm{~s}$ with a mean \pm standard deviation (SD) of 00:50 \pm 01:02. Sightings were classified in $n=7$ marine megafauna groups: whale $(n=3)$, dolphin $(n=1)$, seal $(n=16)$, shark $(n=29)$, ray $(n=4)$, fish $(n=11)$, and turtle $(n=3$; Table 2 and Figure 2). No birds or other marine reptiles were identified in any imagery.

Of these $n=67$ sightings, $n=178$ individuals were recorded, including a school of approximately 100 requiem sharks (Carcharhinus sp.) and $n=1$ unidentified shark egg case. Most taxa $(n=17)$ were identified to species level, while $n=3$ recordings could be identified only to genus level. The remaining $n=9$ individuals could be identified only to family level or above, mainly due to lack of location metadata. Sharks $(n=134)$, fish $(n=17)$, and seals $(n=16)$ comprised the majority of individuals. The most sighted species was gray seal $(n=11)$, followed by porbeagle shark (Lamna nasus, $n=10$ ), and bluntnose sixgill shark (Hexanchus griseus, $n=6$ ).

One gray seal, identified due to a distinct white mark on its lower back (Figure 3) was re-sighted 17 times across three days $(28 / 08 / 2018,30 / 08 / 2018$, and 31/08/2018), resulting in $n=14$ sub-sightings. Additionally, $n=2$ still images of a bottlenose dolphin were classified as sub-sightings, since they were recorded within a 2 -min period of the same operation. In total, these additional $n=16$ sub-sighting data were only included in sighting duration and behavioral analysis (total $n=83$ ).

Location metadata or an approximate region were supplied for $n=44$ sightings. These originated from six main geographical regions (Figure 4), the majority of which were recorded in the North-East Atlantic $(n=24)$. These included locations west of Ireland $(n=7)$, the North Sea, within maritime borders of England, Scotland, Denmark, and Norway $(n=15)$, and the Irish sea ( $n=1$, see UK inset in Figure 4). Further recordings originated from the GoM $(n=9)$, Australia $(n=4)$, south-east Asia $(n=3)$, Brazil $(n=2)$, and the Persian Gulf $(n=2)$.

Recording depths ranged from 13.8 to $3,000 \mathrm{~m}$ (Table 2). The deepest three recordings were of sleeper sharks at 2,650 m, $2,779 \mathrm{~m}$ and an approximate depth of 3,000 $\mathrm{m}$. The shallowest recordings $(13.8-16.4 \mathrm{~m})$ were of common seals, a porbeagle shark, round ribbontail ray, and a hawksbill turtle. The most variable depth-range was observed for gray seals over a vertical 
TABLE 2 | Marine megafauna sightings ( $n=67$ ) compiled into groups, and then identified alphabetically to lowest taxonomic rank, as per Shirihai and Jarrett (2006) and Nelson et al. (2016), including number of animals, sighting duration, location, depth, IUCN Red List threat status for identified species (https://www.iucnredlist.org/), and YouTube URL hyperlinks (blank cells representing footage sourced solely through industry).

\begin{tabular}{lllllll}
\hline $\begin{array}{l}\text { Marine } \\
\text { megafauna } \\
\text { group }\end{array}$ & Scientific name & $\begin{array}{l}\text { Common } \\
\text { name/type }\end{array}$ & $\begin{array}{l}\text { Sightings/ } \\
\text { Animals }(\boldsymbol{n})\end{array}$ & Location & $\begin{array}{l}\text { Sighting } \\
\text { depth }(\mathbf{m})\end{array}$ & $\begin{array}{l}\text { IUCN threat } \\
\text { status }\end{array}$ \\
\hline Whale & $\begin{array}{l}\text { Physeter } \\
\text { macrocepha/us }{ }^{\ddagger}\end{array}$ & Sperm whale & $3 / 3$ & GoM & 900 & Vulnerable \\
& Tursiops truncatus & Bottlenose dolphin & $11^{* / 1-3}$ & North Sea & 26 & Least concern \\
Solphin & Halichoerus grypus & Gray seal & $11^{* *} / 10$ & North-East Atlantic & $71-353$ & Least concern
\end{tabular}

YouTube URLs

Phoca vitulina

Common seal

$4 / 4$

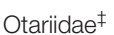

Carcharhinus

melanopterus

Carcharhinus sp.

Carcharias taurus ${ }^{\ddagger}$

Cetorhinus

maximus

Chondrichthyes ${ }^{\ddagger}$

Hexanchus griseus

Sea lion

$1 / 1$

Blacktip reef shark $\quad$ 1/1

Requiem shark $\quad 1 / 100$

Gray nurse shark 2/2

Basking shark

Shark egg case

Bluntnose sixgill

shark

$2 / 3$

$1 / 1$

$6 / 6$

Longfin mako shark $\quad$ 1/1

Isurus paucus ${ }^{\ddagger}$

Lamna nasus

Porbeagle shark

6/6-9

Endangered

Rhincodon typus

\section{$5 / 6$}

North Sea

40

$15-70$

Vulnerable

Western Australia 28

GoM

Vulnerable

Vulnerable

GoM \&

40

Gulf of Thailand,

South China Sea,

and Western

Australia
https://www.youtube.com/watch?v=CHdJllxpTnU

https://www.youtube.com/watch?v=4S6zzd9H5D4

https://www.youtube.com/watch?v=pb-hujQs2dY

https://www.youtube.com/watch?v=bVWooelhhvY https://www.youtube.com/watch?v=G4d1Nd9VBYE https://www.youtube.com/watch?v=41zUzbOvAxk https://www.youtube.com/watch?v=f6l6MDZM9Pc https://www.youtube.com/watch?v=tuKQ7P9Kwig https://www.youtube.com/watch?v=jH3ce4xVpYl https://www.youtube.com/watch?v=F9kxs-Z62hc https://www.youtube.com/watch?v=ngPORIh2EDM https://www.youtube.com/watch?v=4cpBFG6SBks

https://www.youtube.com/watch?v=LamD8ezGuXg https://www.youtube.com/watch?v=rrD57i8qTao https://www.youtube.com/watch?v=QbfOzh2HK_k https://www.youtube.com/watch?v=UrTzfKJUKyE\&t=0s\& list=PLEFA6A4C2B63D71FC\&index $=3$

https://www.youtube.com/watch?v=wsgTxgw9h8| https://www.youtube.com/watch?v=NWI9pp7oNuQ https://www.youtube.com/watch?v=1ex7uTQf4bQ https://www.youtube.com/watch?v=N137nlx5fss https://www.youtube.com/watch?v=R_2zUC23jss https://www.youtube.com/watch?v=8c6EQvPwQy8 https://www.youtube.com/watch?v=eux4oDo-vGU https://www.youtube.com/watch?v=dar3ELXBkbO https://www.youtube.com/watch?v=mvltmqWZ36c https://www.youtube.com/watch?v=vfQcKztCj4c https://www.youtube.com/watch?v=ugcNC719v3A https://www.youtube.com/watch?v=AxAtz_2BtHs https://www.youtube.com/watch?v=CDLlififasi4 https://www.youtube.com/watch?v=BpEyOqFUheY

https://www.youtube.com/watch?v=RsbvJviW1rs https://www.youtube.com/watch?v=4S6zzd9H5D4 https://www.youtube.com/watch?v=sEirbV7VaXE https://www.youtube.com/watch?v=4S6zzd9H5D6 https://www.youtube.com/watch?v=XF3zUGnKzSO 


\section{TABLE 2 | Continued}

\begin{tabular}{|c|c|c|c|c|c|c|c|}
\hline $\begin{array}{l}\text { Marine } \\
\text { megafauna }\end{array}$ & Scientific name & $\begin{array}{l}\text { Common } \\
\text { name/type }\end{array}$ & $\begin{array}{l}\text { Sightings/ } \\
\text { Animals }(n)\end{array}$ & Location & $\begin{array}{l}\text { Sighting } \\
\text { depth }(m)\end{array}$ & $\begin{array}{l}\text { IUCN threat } \\
\text { status }\end{array}$ & YouTube URLs \\
\hline & Somniosus sp. & Sleeper shark & $3 / 3$ & $\begin{array}{l}\text { GoM \& East of } \\
\text { Brazil }\end{array}$ & $\begin{array}{l}2,650- \\
3,000^{+}\end{array}$ & & $\begin{array}{l}\text { https://www.youtube.com/watch?v=B-whabKr_ro } \\
\text { https://www.youtube.com/watch?v=P__rVYdNmE } \\
\text { https://www.youtube.com/watch?v=kPS9Vifm3rk }\end{array}$ \\
\hline & Sphyrnidae ${ }^{\ddagger}$ & Hammerhead shark & $1 / 1$ & & 512 & & https://www.youtube.com/watch?v=N137nlx5fss \\
\hline \multirow[t]{4}{*}{ Ray } & Mobulidae ${ }^{\ddagger}$ & Mobula ray & $1 / 1$ & & 22 & & https://www.youtube.com/watch?v=ltbuUoOYsv4 \\
\hline & ${\text { Myliobatoidei }{ }^{\ddagger}}$ & Stingray & $1 / 1$ & & 44 & & https://www.youtube.com/watch?v=xJHZ1exaz5o \\
\hline & Rhinobatidae $e^{\ddagger}$ & Guitar fish & $1 / 1$ & & 150 & & https://www.youtube.com/watch?v=xJHZ1exaz5o \\
\hline & Taeniurops meyeni & $\begin{array}{l}\text { Round ribbontail } \\
\text { ray }\end{array}$ & $1 / 1$ & Persian Gulf & 16 & Vulnerable & \\
\hline \multirow[t]{6}{*}{ Fish } & Muraenidae ${ }^{\ddagger}$ & Moray eel & $2 / 2$ & GoM & $150-1,500^{\dagger}$ & & $\begin{array}{l}\text { https://www.youtube.com/watch?v=xJHZ1exaz5o } \\
\text { https://www.youtube.com/watch?v=eux4oDo-vGU }\end{array}$ \\
\hline & Serranidae ${ }^{\ddagger}$ & Grouper & $3 / 6$ & & 77 & & $\begin{array}{l}\text { https://www.youtube.com/watch?v=xJHZ1exaz5o } \\
\text { https://www.youtube.com/watch?v=jlGH7nivIEM } \\
\text { https://www.youtube.com/watch?v=QbfOzh2HK_k }\end{array}$ \\
\hline & Mola mola & Ocean sunfish & $1 / 1$ & Western Australia & $125^{\dagger}$ & Vulnerable & https://www.youtube.com/watch?v=DTY24ONHFOU \\
\hline & Molidae & Sunfish & $1 / 4$ & West of Ireland & 27 & & \\
\hline & Thunnus obesus & Bigeye tuna & $1 / 1$ & GoM & 1,070 & Vulnerable & https://www.youtube.com/watch?v=yT1EL9kpel4 \\
\hline & Xiphias gladius $^{\ddagger}$ & Broadbill swordfish & $3 / 3$ & Western Australia & $119-730$ & Least concern & $\begin{array}{l}\text { https://www.youtube.com/watch?v=N137nlx5fss } \\
\text { https://www.youtube.com/watch?v=Bn22jvxfHOE } \\
\text { https://www.youtube.com/watch?v=FEGeSWoB8Bg }\end{array}$ \\
\hline \multirow[t]{2}{*}{ Turtle } & $\begin{array}{l}\text { Eretmochelys } \\
\text { imbricata }\end{array}$ & Hawksbill turtle & $2 / 2$ & Gulf of Thailand & 16 & $\begin{array}{l}\text { Critically } \\
\text { endangered }\end{array}$ & $\begin{array}{l}\text { https://www.youtube.com/watch?v=00ZnrVoVWuY } \\
\text { https://www.youtube.com/watch?v=UyK_9rsd-p4 }\end{array}$ \\
\hline & $\begin{array}{l}\text { Lepidochelys } \\
\text { olivacea }^{\ddagger}\end{array}$ & Olive ridley turtle & $1 / 1$ & & & Vulnerable & https://www.youtube.com/watch?v=ISvMEPAxy0k \\
\hline
\end{tabular}

Records marked with symbols have been divided into further sub-sightings: ${ }^{*} n=3,{ }^{* *} n=24 .{ }^{\dagger}$ Estimated depth by ROV surveyor who uploaded video. ${ }^{\ddagger}$ Included sightings without geographical location (blank cells representing missing information). GoM, Gulf of Mexico. Authors of this paper have endeavored to provide correct links; however, uploaded videos are occasionally removed, and some links may be country-restrictive. 


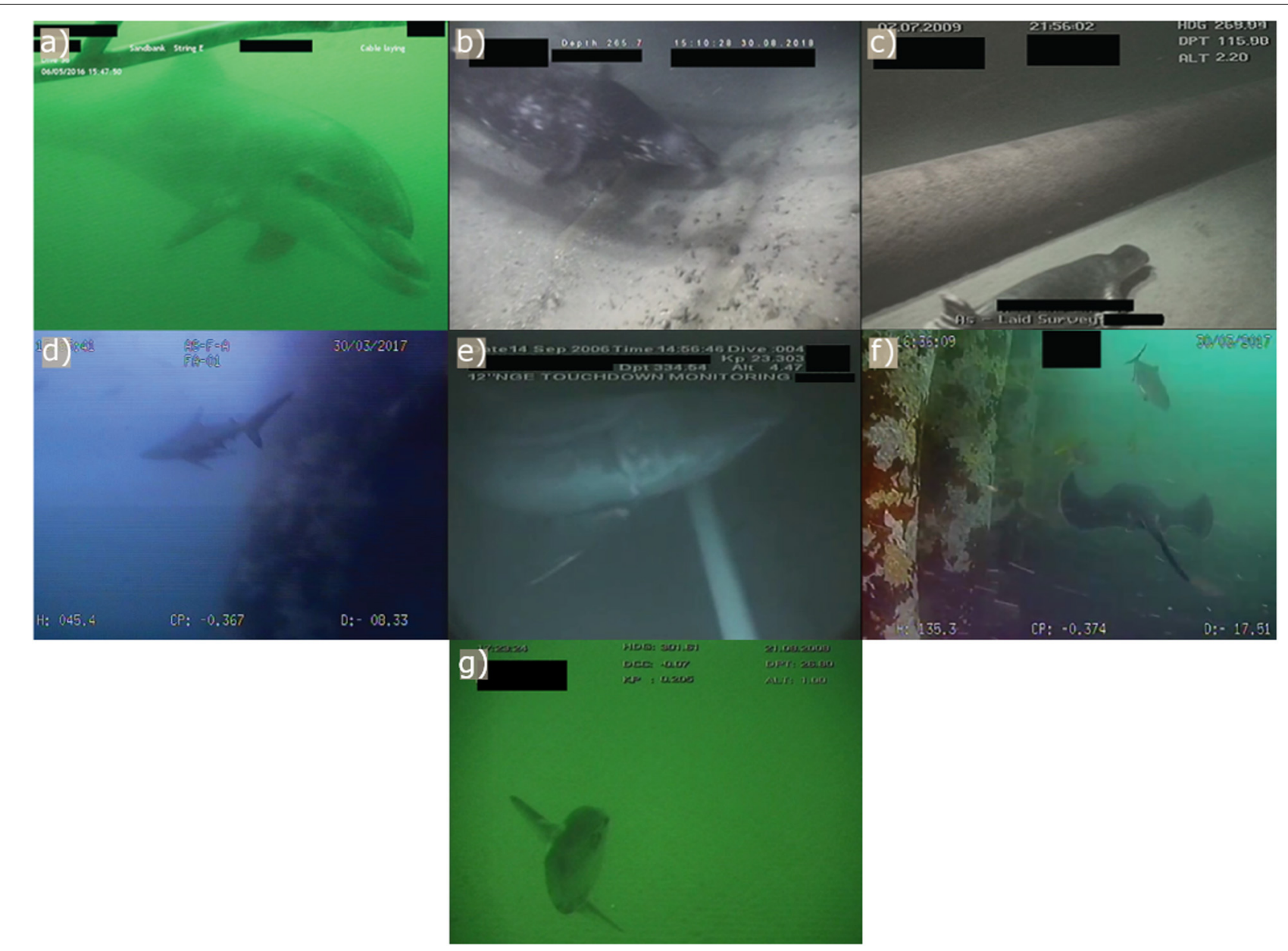

FIGURE 2 | Examples of still images taken from video imagery sourced directly from industry partners showing marine megafauna species close to anthropogenic structures: (a) bottlenose dolphin (Tursiops truncatus), (b) gray seal (Halichoerus grypus), (c) common seal (Phoca vitulina); (d) blacktip reef shark (Carcharhinus melanopterus), (e) basking shark (Cetorhinus maximus), (f) round ribbontail ray (Taeniurops meyeni), and (g) sunfish (Molidae).

depth of $282 \mathrm{~m}$ from 71 to $353 \mathrm{~m}$. No depth information was available in $n=20$ sightings.

Seven types of anthropogenic O\&G structures were identified visibly, or through surveyor comments (Table 3). No data were available from renewable infrastructure. Most sightings were taken during installation or maintenance operations of platforms, followed by pipelines and umbilicals. Megafauna were observed mostly 'approaching' structure $(n=29$; Figure 2), while direct physical contact was recorded on $n=20$ occasions, and 'nocontact' was observed at $n=18$ sightings. On one occasion, whilst crossing over a pipeline, a seal touched the surface, and disturbed the sediment with its flipper. Most commonly observed behavior was interaction followed by searching, and traveling, while foraging and other were observed least (Figure 5). Food-related behaviors (searching and foraging; Figure 6) were observed for seals, sharks and fish, while an interaction between organism and structure/diver was observed in all groups except ray, and traveling was recorded for whale, seal, shark, ray and fish.

A 3-s gray seal foraging attempt was recorded near a concrete pipeline in which the seal chased an unidentified fish, which sought refuge under the pipeline (Figure 6d). Foraging success could not be determined, as camera FOV did not record the outcome. A common seal was also filmed following a pipeline during an inspection in the Irish Sea (Figure 2c). While prey were present in close proximity to both the seal and the pipeline, foraging interactions were not observed. Basking sharks were recorded swimming along a pipeline $(<1 \mathrm{~m}$ from the structure, two clips totaling $39 \mathrm{~s}$ ), and a turtle was recorded swimming past a diver and platform, and came into direct physical contact with both (duration 03:02).

\section{DISCUSSION}

This review evaluated presence and potential behavior of marine megafauna around offshore anthropogenic structures through video sub-surface sightings from opportunistic industrysupplied or openly-available ROV and commercial-diver data collected during GVI or IMR operations. In total, 79 video clips and three still images were collected resulting in 67 


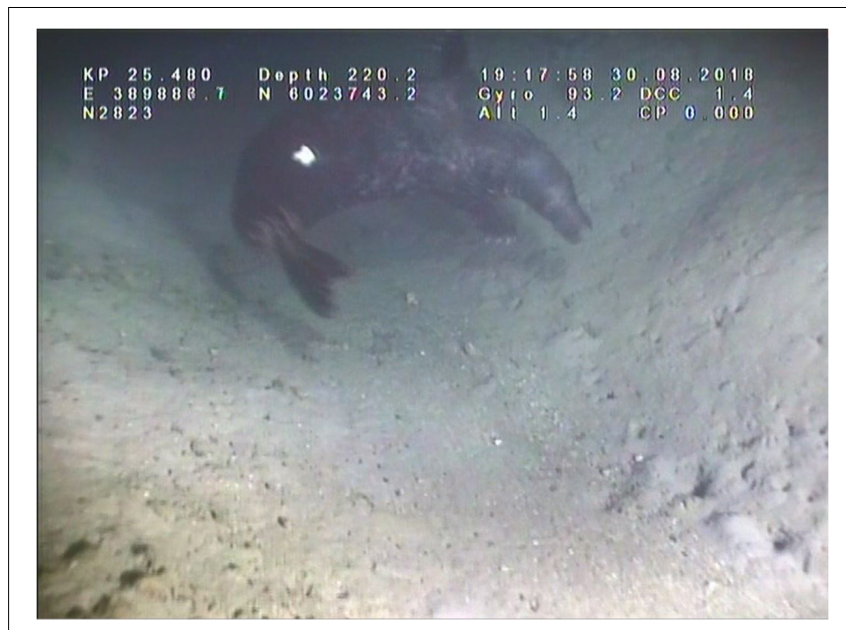

FIGURE 3 | Still image of gray seal (Halichoerus grypus) identified due to white mark on lower back, as a re-occurring individual in subsequent sub-sightings.

sightings of 178 individuals from at least 17 species, 3 genera, and 9 family (or taxonomically above) groups of marine megafauna. This work demonstrated occurrence and potential foraging of marine megafauna in vicinity of anthropogenic structures on a global scale, and the first confirmed visual verification of seals following pipelines. Due to the nature of opportunistically-collected data, only qualitative descriptions were possible. Statistical comparisons would have only been achievable using dedicated-survey data. While data presented here are a 'snapshot', given the thousands of hours of ROV data taken each month, it is conceivable that these observations could magnify quickly into full global data sets within their own right. Consequently, we urge other workers to follow suit, in a bid to quantify the frequency and nature of these events.

Over the last $30+$ years, ROVs have become a dominant tool for subsea operations in the O\&G sector; however, no imagery was sourced from the renewable energy sector. This could be for a number of reasons. Firstly, the renewable industry is newer, and there has been less time for ROV data to have accumulated and reach the various social medial platforms. Secondly, ROV surveys in this sector are likely less common, potentially because renewable energy structures are located in more exacting site conditions (shallow waters, high wind/wave/swell/currents, etc.), making standardized ROV surveys unfeasible operationally.

\section{Structure Association}

Previous acoustic and surface-based visual studies that have detected marine mammals around O\&G structures (e.g., Cremer et al., 2009; Todd et al., 2009, 2016; Thompson et al., 2010; Delefosse et al., 2018), have now been corroborated by the commercial subsea imagery in this study. Presence of other megafauna species such as sharks (Haugen and Papastamatiou, 2019), rays, and turtles (McLean et al., 2017, 2019b) confirm that marine mammals are not unique in their exploitation of resources on/around anthropogenic structures. Individuals approached structures in close proximity, occasionally resulting in direct contact, which is not a behavior associated typically with avoidance (Mackintosh, 1974). Visual evidence of foraging behavior and successful prey capture by seals, sharks and large fish in vicinity of submerged pipelines, umbilicals, and platforms support previous evidence from Russell et al. (2014); Arnould et al. (2015), and Todd et al. (2016) that marine megafauna may target anthropogenic structures as foraging locations. Some of the searching behavior observed in the imagery may well have been simple 'curiosity.' Arnould et al. (2015) also suggested that animals not only take advantage of the actual hard structures themselves, but also benefit potentially from their impact on the surrounding environment through induced currents and subsequent scour on microhabitat.

\section{Diving to New Depths}

To our knowledge, the YouTube imagery of the sleeper shark recorded about $400 \mathrm{~km}$ off the coast of Brazil at a depth of 2,779 m (Supplementary Table 1) could potentially be the deepest recording of a large sleeper shark, Somniosus spp. (ANON, 2012). While the sighting of the sleeper shark at 3,000 m could suggest an even deeper observation, estimated depth could not be confirmed, since it was only mentioned in the video title, and not on-screen, or in video commentary. Morphological similarities make it impossible to distinguish Somniosus spp., which are 'virtually impossible to distinguish based solely on imagery' (Gallant, 2012), and require molecular analysis (Benz et al., 2007). While smaller species of sleeper sharks (Centroscymnus spp.), including Portuguese dogfish, Centroscymnus coelolepis, are known to inhabit deeper waters up to 3,675 m (Compagno, 1984), only a handful of sightings of Somniosus spp. have been published in the western Atlantic. These included the ROV recording of the first report of a somniosid shark in the southern Colombian Caribbean (1,820 m; Acero et al., 2018) and northern GoM (1,423 m; Benfield et al., 2008). The maximum confirmed depth of a large sleeper shark (which was also the earliest sighting for this review), was recorded at 2,647 $\mathrm{m}$ (Benz et al., 2007). This was also the first reliable sighting of Somniosus spp. in the GoM and one of the deepest records for any shark species. These data, based purely on industrial ROV imagery demonstrates significant value of these industrial recordings.

In this study, recorded depths of one of the sperm whales $(\sim 900 \mathrm{~m})$ and gray seals (up to $353 \mathrm{~m}$ ) were also near the limits of each species' known capacity. Tracking studies have recorded sperm whale modal dives at around $600 \mathrm{~m}$ (Watwood et al., 2006), while their foraging dives have been tracked to 1,185 $\mathrm{m}$ and possibly 2,000 $\mathrm{m}$ (Watkins et al., 1993; Watwood et al., 2006; Whitehead, 2018). Gray seals have been tracked diving to at least $412 \mathrm{~m}$ (Beck et al., 2003). Overall, tagging data require substantial financial and logistical investment, can be invasive and deeply traumatic for captured animals (especially marine mammals, consequently altering behavior and biasing results), whereas recordings used for this review were opportunistic. 


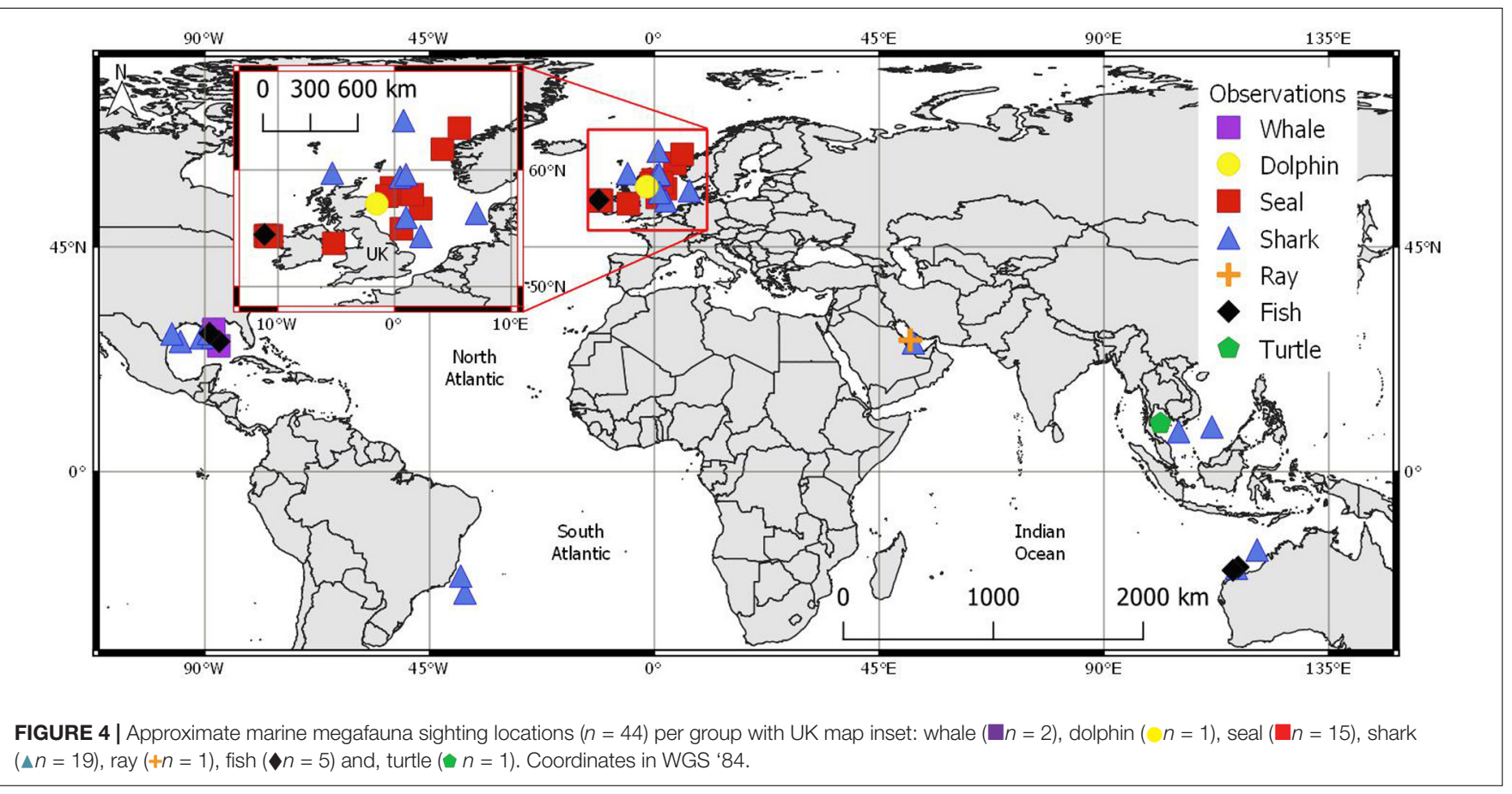

TABLE 3 | Types of anthropogenic O\&G structure, including descriptions based on Schlumberger (2019), that were identified during marine megafauna encounters, followed by number of recordings $(n=67)$.

\begin{tabular}{|c|c|c|}
\hline Structure & Description & Sightings $(n)$ \\
\hline BlowOut Preventer (BOP) & Series of hydraulic pumps to close well off in emergency & 6 \\
\hline Jumper & Flexible jumper linking pipes to various structures & 1 \\
\hline Pipeline & System of pipes to transport oil or gas from production site (on seabed or submerged) & 13 \\
\hline Platform & O\&G production platform, including parts of platform visible (e.g., caissons) & 26 \\
\hline Riser & Pipe connecting BOP to rig & 1 \\
\hline Umbilical & (Buried) cables containing different cores used to carry electrical power, chemicals and control fluids & 10 \\
\hline Wellhead & Surface termination of a wellbore utilized for drilling operations & 10 \\
\hline
\end{tabular}

\section{Utilization of ROV Data}

Gates et al. (2017) and Macreadie et al. (2018) highlighted the value of collaboration between scientists and industry, specifically in relation to the large volume of ROV datasets that could increase scientific discovery and enhance likelihood of encountering large enigmatic marine organisms. The Scientific and Environmental ROV Partnership using Existing Industrial Technology (SERPENT) Project produced 40 peer-reviewed publications from over 120 visits to offshore infrastructure (Gates et al., 2017). These publications include deepest recorded scalloped hammerhead (Sphyrna lewini) and southern sunfish (Mola ramsayi), as well as the first in situ observation of an oarfish, Regalecus glesne Gates et al. (2017). Results such as these, and those summarized in Macreadie et al. (2018), highlight benefits of industry and scientific cooperation and collaboration.

Increased availability of industry/research collaboration consortia [e.g., Influence of man-made Structures in the Ecosystem (INSITE) in the North Sea, and National Decommissioning Research Institute (NDRI) in Australia] could potentially facilitate data sharing across institutions. In addition, commercial industrial/environmental monitoring suppliers providing protected research time to staff would allow a vast amount of research to proceed; however, the reality is that industry has its 'preferred' users, so access to these proprietary data is often merely knowing the 'right' people, being in the 'right place at the right time', and having the drive (and the time) to complete 'unremunerated' analysis of data in a bid to further the field.

ROV data come generally in two forms (1) dedicated, scientifically designed surveys, often collected by instrumentally augmented (non-standard) ROVs for research purposes (e.g., McLean et al., 2019a), and (2) non-scientific surveys, collected by standard, off-the-shelf ROVs for industry purposes, where the analyst has no control over survey design/sensor configuration, distance to objects, scale, FOV, or even knowledge on make and model of ROV (e.g., Todd et al., 2018, 2019). Consequently, analysis options for these types of data differ. Dedicated scientific surveys can make use of techniques such as machine learning (e.g., Piechaud et al., 2019), whereas applicability of 


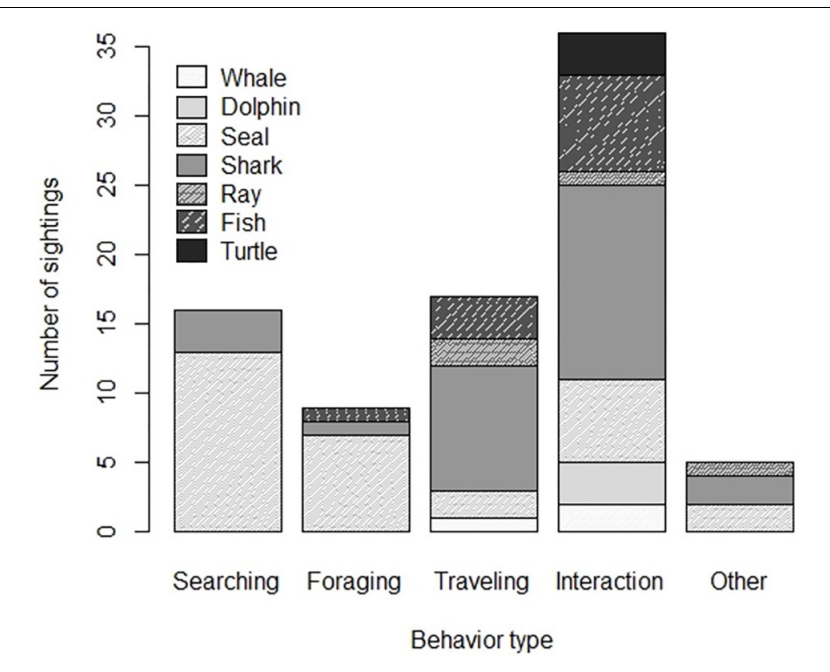

FIGURE 5 | Summary of behavior types observed across recordings (including sub-sightings, $n=83$ ).

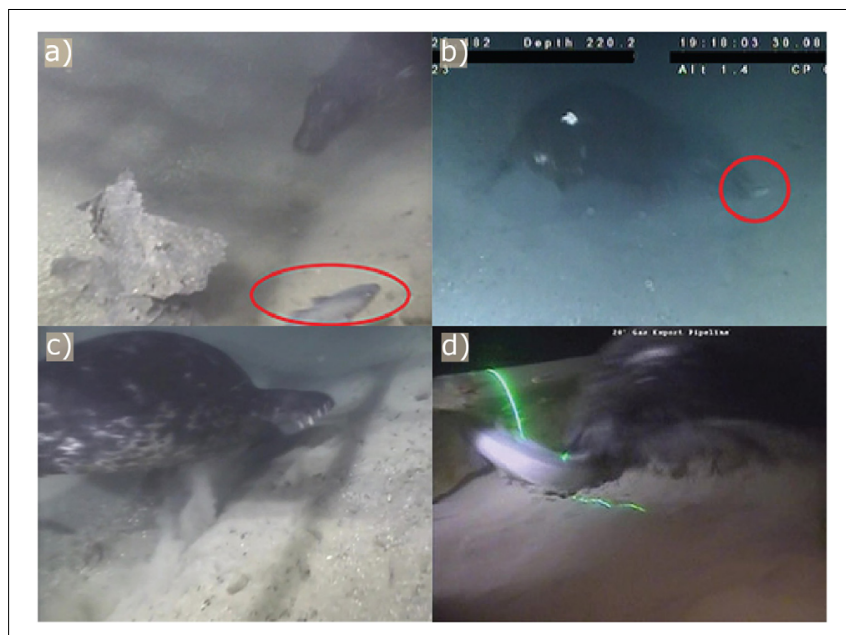

FIGURE 6 | Examples of foraging attempts and successful prey capture (behavior classification 2) in the vicinity of anthropogenic O\&G structures by a gray seal (Halichoerus grypus). (a) Possible foraging attempt on gadoid fish (Gadidae), highlighted by red ellipse, (b) foraging attempt on unidentified fish, highlighted by red circle, (c) possible foraging attempt on subsurface prey, and, (d) successful fish capture.

these techniques to industry data are, to the best of our knowledge, untested.

Making use of ROV imagery and commercial-diver recordings, which are regularly collected en masse for the O\&G industry worldwide (at the cost of billions of pounds each year) has multiple advantages. Collaborations can be formed between industry and scientists, allowing studies on habitats that are otherwise inaccessible, improving our knowledge of poorly-understood species (Gates et al., 2017; McLean et al., 2018a, 2020). Imagery collected routinely for industrial purposes can be made available to researchers for free, avoiding additional funding and effort. Industrial ROVs are often equipped with other useful sensors, such as hydrophones, Sound Navigation And Ranging (SONAR), or motion sensors (Muyzert et al., 2015; Macreadie et al., 2018), data from which can potentially be analyzed without requiring added cost or license approvals. Tapping into these surveys can reduce environmental disturbance from conducting duplicate surveys (Jones, 2009). To address major knowledge gaps and conservation challenges, it has been suggested recently to take advantage of ever-increasing supply of publicly available, open-source data on social media platforms to supplement conventional research protocols (Klemann-Junior et al., 2017; McKinley et al., 2017; Mancini et al., 2019; Pace et al., 2019; Parton et al., 2019). This has been demonstrated to be a reliable tool for obtaining cetacean-distribution data (Hann et al., 2018; Pace et al., 2019); therefore, collecting ROV data from international public-domain platforms can aid research purposes on a global scale. There are additional caveats on public data, e.g., only interesting/exciting sections are posted which makes effort impossible to determined.

Industrial ROV surveys have several disadvantages, most obvious of which is a complete lack of ecological survey design, making robust statistical analysis difficult (e.g., lack of pre-installation 'control' data, short temporal scale, variable seasonality, etc.). While time format for scientific data collection is standardized to GMT, time stamps on industrial imagery were supplied without format clarifications, necessitating assumption of local time stamps. Since data were also collected across different time zones, seasonality of ROV recordings was difficult to assess. While most data were collected between August and October for the northern hemisphere, a seasonal trend toward the summer period could be suggested. This could be a consequence of increase in effort and visibility during periods of clement weather, but could also suggest seasonality of megafauna presence in the vicinity of anthropogenic structures for e.g., feeding, breeding. This inference, however, remains unquantifiable from these data. While again, it would be interesting to confer this trend with the southern hemisphere, not enough data were collected there to allow for such a comparison. Additionally, presence of the ROV itself may alter behavior or presence of animals being surveyed (Hudson et al., 2005; Andaloro et al., 2013). For example, previous research has shown artificial light alters predator-prey relationships (reviewed in Longcore and Rich, 2004). This is particularly the case for seals, which have shown significantly increased feeding behavior with artificial lights (Yurk and Trites, 2000). No information was available as to presence/absence of lights on the ROV, diver, or offshore installation, meaning any inferences on periodicity were not possible.

Overall, quality of video imagery on industrial ROV surveys is often low priority, since surveys are designed mainly to use other technologies, such as pipe tracker and multibeam, lacking provision of a distance-range estimator (Macreadie et al., 2018). Additionally, several recordings were not provided with location or depth information, necessary for a reliable species identification. Improving design of ROV surveys could be achieved through collection of High Definition (HD) imagery, a laser range-distance estimator, and inclusion 
of necessary metadata as discussed in Todd et al. (2019) and McLean et al. (2020).

Dates of available data in this study were a consequence of various factors, as opposed to a lack of available ROV data. While the first ROVs were available commercially to the US Navy in the late 1960s (Hudson et al., 2005), the majority of imagery in this study originated post-2006. This may have been for a number of reasons. Firstly, data availability has increased with access to the Internet, accessible by the public since August 1991 and the popularity of YouTube (founded in 2005) over the last few years. Additionally, the greatest issue of industrial ROV data is the restricted access to commercially sensitive imagery, often protected by NDAs; therefore, partnerships between industry and scientists are invaluable to gain access to otherwise inaccessible data and researchers should be encouraged to consult archived data (Sward et al., 2019; Todd et al., 2019; McLean et al., 2020).

\section{Marine Megafauna Sightings in the Face of Decommissioning}

Of 17 taxa identified here to species level, 13 are listed on the IUCN Red List as threatened species, one of which, the hawksbill turtle, is critically endangered. Other taxa that could not be identified to species level include many that are listed as data deficient. Overall, presence of marine megafauna at offshore industrial sites warrants further investigation and consideration of potential interactions between megafauna and O\&G installations.

Marine mammals have been detected visually and acoustically around these structures (e.g., platforms and pipelines), and it has been suggested that they target these sites for foraging (Todd et al., 2009, 2016; Russell et al., 2014; Orr et al., 2017; Delefosse et al., 2018). If echolocating cetaceans cluster regularly around installations within the $500-\mathrm{m}$ exclusion zones, then it is highly likely they have been omitted unintentionally from historical visual and acoustic population surveys. This is because HighFrequency (HF) sound attenuates rapidly underwater (Urick, 1983), especially for odontocetes that emit Narrow Band HF (NBHF) echolocation clicks, such as harbor porpoises (Au, 1999; Teilmann et al., 2002; Villadsgaard et al., 2007). This limits survey detection to $250-300 \mathrm{~m}$ of the hydrophone (onaxis) at best, in ideal-propagation conditions (Todd et al., 2015, 2016), resulting in potentially significant underestimations of their true population status, e.g., by Small Cetacean Abundance in the North Sea or SCANS (Hammond et al., 2002, 2013, 2017). Future studies utilizing previously collected and archived data to study potential associations of marine mammals with offshore anthropogenic infrastructure, must therefore account for the fact that data likely do not include animals in close proximity (i.e., within the typical 500-m shipping exclusion zone) of offshore structures.

Fowler et al. (2014, 2018) and van Elden et al. (2019) highlighted key concerns with complete decommissioning and how it could affect marine ecosystems. The consensus was that a case-by-case approach is required, in which careful consideration of environmental impacts of removal of each installation would be required, as opposed to a blanket policy.
The role these structures play for megafauna on a population level, acting as a network of protected areas with further potential to provide spatially predictable foraging locations, is still unknown. In addition, the notion that some offshore installations can act potentially as 'ecological mortality traps' warrants further investigation. For example, there are confirmed industry records (Victoria L. G. Todd, unpublished obs.) that whale sharks targeting offshore O\&G installations suffer fatal interactions with support vessel propeller shafts, and vessel collisions. Clearly, continued research is necessary to address these major knowledge gaps.

\section{CONCLUSION AND RECOMMENDATIONS}

This manuscript provides a subsea account of marine megafauna presence and initial accounts of feeding behavior in vicinity of anthropogenic structures using visual ROV and commercialdiver data collected for industrial purposes. It also highlights the deepest recording of a sleeper shark in published literature and the first confirmed visual evidence of seals following pipelines. Future research on this topic could focus on non-commercial, recreational imagery from divers around offshore installations, and include Internet searches using non-technical terms, such as 'cool deep-sea fish gets eaten by shark near oil rig.'

In the face of imminent decommissioning, our understanding of the role these structures play in the lives of marine megafauna is incomplete, at best. Investigations into use of ROV imagery demonstrate potential for collaborations between researchers and industry, that have capacity to unlock a vast wealth of data, which can be used to make more informed decisions regarding future management of these structures.

\section{DATA AVAILABILITY STATEMENT}

Links to publicly available YouTube videos are provided in Table 2 and Supplementary Table 1. Other imagery is protected by NDA from industrial partners.

\section{ETHICS STATEMENT}

Ethical review and approval was not required for the animal study because observations of animals were sourced from YouTube videos. Written informed consent was not obtained from the individual(s) for the publication of any potentially identifiable images or data included in this article.

\section{AUTHOR CONTRIBUTIONS}

VT conceived the idea, sourced imagery, and contributed to drafting of the manuscript. LL sourced imagery and contributed to drafting of the manuscript. LW oversaw analysis and contributed to drafting of the manuscript. IP sourced imagery. 
$\mathrm{AH}$ edited a previous draft. SC administered the analysis. IT sourced imagery. PM and DM contributed to manuscript drafts.

\section{ACKNOWLEDGMENTS}

We would like to thank Jane Warley née Gardiner (formerly OSC), Irene Susini (OSC), and all operators who contributed

\section{REFERENCES}

Acero, A. P., Polo-Silva, C. J., León, J., and Puentes, V. (2018). First report of a sleeper shark (Somniosus sp.) in the southern Colombian Caribbean. J. Appl. Ichthyol. 34, 981-983. doi: 10.1111/jai.13712

Ache, K. A., and Wallace, L. S. (2008). Human papillomavirus vaccination coverage on YouTube. Am. J. Prev. Med. 35, 389-392. doi: 10.1016/j.amepre.2008.06.029

Andaloro, F., Ferraro, M., Mostarda, E., Romeo, T., and Consoli, P. (2013). Assessing the suitability of a remotely operated vehicle (ROV) to study the fish community associated with offshore gas platforms in the Ionian Sea: a comparative analysis with underwater visual censuses (UVCs). Helgol. Mar. Res. 67, 241-250. doi: 10.1007/s10152-012-0319-y

ANON (2012). Video: Sleeper Shark at Over 9100 Feet $(2770$ m) Deep off Brazil [Online]. The Dorsal Fin - Shark News. Available online at: http://www.thedorsalfin.com/shark-news-stories/greenland-shark-vide-over9100-feet-deep-2770m-off-coast-of-brazil/ (accessed July 05, 2019).

Arnould, J. P., Monk, J., Ierodiaconou, D., Hindell, M. A., Semmens, J., Hoskins, A. J., et al. (2015). Use of anthropogenic sea floor structures by Australian fur seals: potential positive ecological impacts of marine industrial development? PLoS One 10:e0130581. doi: 10.1371/journal.pone.0130581

Au, W. W. L. (1999). Transmission beam pattern and echolocation signals of a harbour porpoise (Phocoena phooena). J. Acoust. Soc. Am. 106, 3699-3705. doi: $10.1121 / 1.428221$

Beck, C. A., Bowen, W. D., McMillan, J. I., and Iverson, S. J. (2003). Sex differences in the diving behaviour of a size-dimorphic capital breeder: the grey seal. Anim. Behav. 66, 777-789. doi: 10.1006/anbe.2003.2284

Benfield, M. C., Thompson, B. A., and Caruso, J. H. (2008). The second report of a sleeper shark (Somniosus (Somniosus) sp.) from the bathypelagic waters of the northern Gulf of Mexico. Bull. Mar. Sci. 82, 195-198.

Benz, G. W., Hoffmayer, E. R., Driggers, W. B., Allen, D., Bishop, L. E., and Brown, D. A. (2007). First record of a sleeper shark in the western Gulf of Mexico and comments on taxonomic uncertainty within Somniosus (Somniosus). Bull. Mar. Sci. 80, 343-351.

Bishop, M. J., Mayer-Pinto, M., Airoldi, L., Firth, L. B., Morris, R. L., Loke, L. H., et al. (2017). Effects of ocean sprawl on ecological connectivity: impacts and solutions. J. Exp. Mar. Biol. Ecol. 492, 7-30. doi: 10.1016/j.jembe.2017.01.021

Chen, J., Xiao, L., Peng, C., Ye, Z., Wang, D., Yang, Y., et al. (2019). Socially controlled male-to-female sex reversal in the protogynous orange-spotted grouper, Epinephelus coioides. J. Fish Biol. 94, 414-421. doi: 10.1111/jfb.13911

Cheung, W. W. L., Lam, V. W. Y., Sarmiento, J. L., Kearney, K., Watson, R., and Pauly, D. (2009). Projecting global marine biodiversity impacts under climate change scenarios. Fish Fish. 10, 235-251. doi: 10.1111/j.1467-2979.2008. 00315.x

Compagno, L., Dando, M., and Fowler, S. (2004). Sharks of the World. London: Harper Collins Publishers.

Compagno, L. J. V. (1984). FAO Species Catalogue. Sharks of the World. An Annotated and Illustrated Catalogue of Shark Species Known to Date. Part 1 Hexanchiformes to Lamniformes. FAO Fisheries Synopsis, Vol. 4. Rome: Food and Agriculture Organization, 1-249.

Coolen, J. W. P., and Jak, R. G. (2018). RECON: Reef Effects of Structures in the North Sea: Island or Connections? Den Helder: Wageningen Marine Research.

Cowan, J. H., and Rose, K. A. (2016). "Oil and gas platforms in the Gulf of Mexico: their relationship to fish and fisheries," in Fisheries and Aquaculture in the Modern World, ed. H. Makkola (London: IntechOpen). data to this project. Also, thanks are due everyone who posted ROV/diver imagery to YouTube.

\section{SUPPLEMENTARY MATERIAL}

The Supplementary Material for this article can be found online at: https://www.frontiersin.org/articles/10.3389/fmars. 2020.00230/full\#supplementary-material

Cremer, M. J., Barreto, A. S., Silva Hardt, F. A., Tonello Junior, A. J., and Mounayer, R. (2009). Cetacean occurrence near an offshore oil platform in southern Brazil. Biotemas 22, 247-251.

Delefosse, M., Rahbek, M. L., Roesen, L., and Clausen, K. T. (2018). Marine mammal sightings around oil and gas installations in the central North Sea. J. Mar. Biol. Assoc. U.K. 98, 993-1001. doi: 10.1017/S0025315417000406

Dirzo, R., Young, H. S., Galetti, M., Ceballos, G., Isaac, N. J. B., and Collen, B. (2014). Defaunation in the anthropocene. Science 345, 401-406. doi: 10.1126/ science. 1251817

Duncan, I., Yarwood-Ross, L., and Haigh, C. (2013). YouTube as a source of clinical skills education. Nurse Educ. Today 33, 1576-1580. doi: 10.1016/j.nedt.2012.12. 013

FLOWW (2014). Best Practice Guidance for Offshore Renewable Developments: Recommendations for Fisheries Liaison. Edinburgh: The Fishing Liaison with Offshore Wind and Wet Renewables Group.

Fowler, A. M., Jørgensen, A.-M., Svendsen, J. C., Macreadie, P. I., Jones, D. O., Boon, A. R., et al. (2018). Environmental benefits of leaving offshore infrastructure in the ocean. Front. Ecol. Environ. 16:571-578. doi: 10.1002/fee. 1827

Fowler, A. M., Macreadie, P. I., Jones, D. O. B., and Booth, D. J. (2014). A multi-criteria decision approach to decommissioning of offshore oil and gas infrastructure. Ocean Coast. Manag. 87, 20-29. doi: 10.1016/j.ocecoaman.2013. 10.019

Friedlander, A. M., Ballesteros, E., Fay, M., and Sala, E. (2014). Marine communities on oil platforms in Gabon, West Africa: high biodiversity oases in a low biodiversity environment. PLoS One 9:e103709. doi: 10.1371/journal.pone. 0103709

Fujii, T., Walls, A., and Horsfield, M. (2014). "Is there a net benefit from offshore structures?" in Proceedings of the SPE International Conference on Health, Safety, and Environment: Society of Petroleum Engineers, Long Beach, CA, 9.

Gallant, J. (2012). RE: Video: Sleeper Shark at Over 9100 Feet Deep (2770m) off Brazil. Type to TheDorsalFin. Available online at: http://www.thedorsalfin.com/shark-news-stories/greenland-shark-videover-9100-feet-deep-2770m-off-coast-of-brazil/ (accessed February 21, 2012).

Gates, A. R., Benfield, M. C., Booth, D. J., Fowler, A. M., Skropeta, D., and Jones, D. O. B. (2017). Deep-sea observations at hydrocarbon drilling locations: contributions from the SERPENT project after 120 field visits. Deep Sea Res. Part II Top. Stud. Oceanogr. 137, 463-479. doi: 10.1016/j.dsr2.2016.07.011

Guerin, A. J. (2009). Marine Communities of North Sea Offshore Platforms, and the Use of Stable Isotopes to Explore Artificial Reef Food Webs. Ph.D. thesis, University of Southampton, Southampton.

Hammond, P., Berggren, P., Benke, H., Borchers, D., Collet, A., Heide-Jørgensen, M., et al. (2002). Abundance of harbour porpoise and other cetaceans in the North Sea and adjacent waters. J. Appl. Ecol. 39, 361-376. doi: 10.1046/j.13652664.2002.00713.x

Hammond, P. S., Lacey, C., Gilles, A., Viquerat, S., Börjesson, P., Herr, H., et al. (2017). Estimates of Cetacean Abundance in European Atlantic Waters in Summer 2016 From the SCANS-III Aerial and Shipboard Surveys. Bonn: ASCOBANS.

Hammond, P. S., Macleod, K., Berggren, P., Borchers, D. L., Burt, L., Cañadas, A., et al. (2013). Cetacean abundance and distribution in European Atlantic shelf waters to inform conservation and management. Biol. Conserv. 164, 107-122. doi: 10.1016/j.biocon.2013.04.010 
Hann, C. H., Stelle, L. L., Szabo, A., and Torres, L. G. (2018). Obstacles and opportunities of using a mobile app for marine mammal research. ISPRS Int. J. Geo Inform. 7:169. doi: 10.3390/ijgi7050169

Haugen, J. B., and Papastamatiou, Y. (2019). Observation of a porbeagle shark Lamna nasus aggregation at a North Sea oil platform. J. Fish Biol. 95, 1496-1499. doi: $10.1111 /$ jfb.14149

Henry, L.-A., Mayorga-Adame, C. G., Fox, A. D., Polton, J. A., Ferris, J. S., McLellan, F., et al. (2018). Ocean sprawl facilitates dispersal and connectivity of protected species. Sci. Rep. 8:11346.

Hudson, I. R., Jones, D. O. B., and Wigham, D. B. (2005). A review of the uses of work-class ROVs for the benefits of science: lessons learned from the SERPENT project. Underw. Technol. 26, 83-88. doi: 10.3723/175605405784426637

Hvass, H. (1978). Reptiles \& Amphibians of the World. London: Methuen \& Co Ltd.

IPBES (2019). Global Assessment Report on Biodiversity and Ecosystem Services of the Intergovernmental Science-Policy Platform on Biodiversity and Ecosystem Services. Bonn: IPBES Secretariat.

Jefferson, T. A., Webber, M. A., and Pitman, R. L. (2015). Marine Mammals of the World: A Comprehensive Guide to Their Identification. Cambridge, MA: Academic Press.

Jones, D. O. (2009). Using existing industrial remotely operated vehicles for deepsea science. Zool. Scr. 38(Suppl. 1), 41-47. doi: 10.1111/j.1463-6409.2007. 00315.x

Jørgensen, D. (2009). An oasis in a watery desert? Discourses on an industrial ecosystem in the Gulf of Mexico Rigs-to-Reefs program. Hist. Technol. 25, 343-364. doi: 10.1080/07341510903313030

Jørgensen, D. (2012). OSPAR's exclusion of rigs-to-reefs in the North Sea. Ocean Coast. Manag. 58, 57-61. doi: 10.1016/j.ocecoaman.2011.12.012

Jørgensen, T., Løkkeborg, S., and Soldal, A. V. (2002). Residence of fish in the vicinity of a decommissioned oil platform in the North Sea. ICES J. Mar. Sci. 59, S288-S293.

Kaiser, M. J., and Pulsipher, A. G. (2005). Rigs-to-reef programs in the Gulf of Mexico. Ocean Dev. Int. Law 36, 119-134. doi: 10.1080/00908320590943990

Kajiura, S. M. (2003). Electroreception in neonatal bonnethead sharks, Sphyrna Tiburo. Mar. Biol. 143, 603-611. doi: 10.1007/s00227-003-1099-3

Kajiura, S. M., and Holland, K. N. (2002). Electroreception in juvenile scalloped hammerhead and sandbar sharks. J. Exp. Biol. 205, 3609-3621.

Kalmijn, A. J. (1982). Electric and magnetic field detection in elasmobranch fishes. Science 218, 916-918. doi: 10.1126/science.7134985

Kempster, R. M., Hart, N. S., and Collin, S. P. (2013). Survival of the stillest: predator avoidance in shark embryos. PLoS One 8:e52551. doi: 10.1371/journal. pone.0052551

Klemann-Junior, L., Vallejos, M. A. V., Scherer-Neto, P., and Vitule, J. R. S. (2017). Traditional scientific data vs. uncoordinated citizen science effort: a review of the current status and comparison of data on avifauna in Southern Brazil. PLoS One 12:e0188819. doi: 10.1371/journal.pone.0188819.t002

Klimley, A. P. (1993). Highly directional swimming by scalloped hammerhead sharks, Sphyrna lewini, and subsurface irradiance, temperature, bathymetry and geomagnetic field. Mar. Biol. 117, 1-22. doi: 10.1007/bf00346421

Klimley, A. P., Beavers, S. C., Curtis, T. H., and Jorgensen, S. J. (2002). Movements and swimming behavior of three species of sharks in La Jolla Canyon, California. Environ. Biol. Fish. 63, 117-135. doi: 10.1023/A:1014200301213

Langhamer, O., and Wilhelmsson, D. (2009). Colonisation of fish and crabs of wave energy foundations and the effects of manufactured holes - a field experiment. Mar. Environ. Res. 68, 151-157. doi: 10.1016/j.marenvres.2009.06.003

Larcom, E. A., McKean, D. L., Brooks, J. M., and Fisher, C. R. (2014). Growth rates, densities, and distribution of Lophelia pertusa on artificial structures in the Gulf of Mexico. Deep Sea Res. Part I Oceanogr. Res. Pap. 85, 101-109. doi: 10.1016/j.dsr.2013.12.005

Lohoefener, R., Hoggard, W., Mullin, K., Roden, C., and Rogers, C. (1990). Association of Sea Turtles with Petroleum Platforms in the North-Central Gulf of Mexico. New Orleans, LA: U. S. Department of the Interior, Minerals Management Service.

Løkkeborg, S., Humborstad, O. B., Jørgensen, T., and Soldal, A. V. (2002). Spatiotemporal variations in gillnet catch rates in the vicinity of North Sea oil platforms. ICES J. Mar. Sci. 59, S294-S299.

Longcore, T., and Rich, C. (2004). Ecological light pollution. Front. Ecol. Environ. 2:191-198. doi: 10.1890/1540-92952004002[0191:ELP]2.0.CO;2
Mackintosh, N. J. (1974). The Psychology of Animal Learning. Cambridge, MA: Academic Press.

Macreadie, P. I., Fowler, A. M., and Booth, D. J. (2011). Rigs-to-reefs: will the deep sea benefit from artificial habitat? Front. Ecol. Environ. 9:455-461. doi: $10.1890 / 100112$

Macreadie, P. I., Fowler, A. M., and Booth, D. J. (2012). Rigs-to-reefs policy: can science trump public sentiment? Front. Ecol. Environ. 10:179-180. doi: 10.1890/ 12.wb.013

Macreadie, P. I., McLean, D. L., Thomson, P. G., Partridge, J. C., Jones, D. O. B., Gates, A. R., et al. (2018). Eyes in the sea: unlocking the mysteries of the ocean using industrial, remotely operated vehicles (ROVs). Sci. Total Environ. 634, 1077-1091. doi: 10.1016/j.scitotenv.2018.04.049

Mancini, F., Coghill, G. M., and Lusseau, D. (2019). Quantifying wildlife watchers' preferences to investigate the overlap between recreational and conservation value of natural areas. J. Appl. Ecol. 56, 387-397. doi: 10.1111/1365-2664.13274

Martin, C. J. B., and Lowe, C. G. (2010). Assemblage structure of fish at offshore petroleum platforms on the San Pedro shelf of Southern California. Mar. Coas. Fish. 2, 180-194. doi: 10.1577/C09-037.1

Maxwell, S. M., Broderick, A. C., Dutton, P. H., Fossette-Halot, S., Fuentes, M. M., and Reina, R. (2019). Advances in the biology and conservation of marine turtles. Front. Mar. Sci. 6:9. doi: 10.3389/fmars.2019.00009

McClellan, C. M., Brereton, T., Dell'Amico, F., Johns, D. G., Cucknell, A.-C., Patrick, S. C., et al. (2014). Understanding the distribution of marine megafauna in the English channel region: identifying key habitats for conservation within the busiest seaway on earth. PLoS One 9:e89720. doi: 10.1371/journal.pone. 0089720

McKinley, D. C., Miller-Rushing, A. J., Ballard, H. L., Bonney, R., Brown, H., CookPatton, S. C., et al. (2017). Citizen science can improve conservation science, natural resource management, and environmental protection. Biol. Conserv. 208, 15-28.

McLean, D., Gates, A., Benfield, M., Bond, T., Booth, D., Bunce, M., et al. (2020). Enhancing the global scientific value of industry remotely operated vehicles (ROVs). Front. Mar. Sci. (in press).

McLean, D., Taylor, M., Ospina, A. G., and Partridge, J. (2019a). An assessment of fish and marine growth associated with an oil and gas platform jacket using an augmented remotely operated vehicle. Continent. Shelf Res. 179, 66-84. doi: 10.1016/j.csr.2019.04.006

McLean, D. L., Macreadie, P., White, D. J., Thomson, P. G., Fowler, A., Gates, A. R., et al. (2018a). "Understanding the global scientific value of industry ROV data, to quantify marine ecology and guide offshore decommissioning strategies," in Proceedings of the Offshore Technology Conference Asia, (Kuala Lumpur: Offshore Technology Conference).

McLean, D. L., Partridge, J. C., Bond, T., Birt, M. J., Bornt, K. R., and Langlois, T. J. (2017). Using industry ROV videos to assess fish associations with subsea pipelines. Continent. Shelf Res. 141, 76-97. doi: 10.1016/j.csr.2017.05.006

McLean, D. L., Taylor, M. D., Partridge, J. C., Gibbons, B., Langlois, T. J., Malseed, B. E., et al. (2018b). Fish and habitats on wellhead infrastructure on the north west shelf of Western Australia. Continent. Shelf Res. 164, 10-27. doi: 10.1016/j. csr.2018.05.007

McLean, D. L., Vaughan, B. I, Malseed, B. E., and Taylor, M. D. (2019b). Fishhabitat associations on a subsea pipeline within an Australian Marine Park. Mar. Environ. Res. 153:104813. doi: 10.1016/j.marenvres.2019.104813

Meyer, C. G., Holland, K. N., and Papastamatiou, Y. P. (2005). Sharks can detect changes in the geomagnetic field. J. R. Soc. Interf. 2, 129-130. doi: 10.1098/rsif. 2004.0021

Meyer, K. S., Li, Y., and Young, C. M. (2018). Oceanographic and biological influences on recruitment of benthic invertebrates to hard substrata on the Oregon shelf. Estuar. Coast. Shelf Sci. 208, 1-8. doi: 10.1016/j.ecss.2018.04.037

Muyzert, E., Welker, K., Cooper, I., Bittleston, S., Combee, L., Ross, R., et al. (2015). Marine Seismic Survey Systems and Methods Using Autonomously or Remotely Operated Vehicles. Google Patents No. WO2012036814A3.

Nelson, J. S., Grande, T. C., and Wilson, M. V. (2016). Fishes of the World. Hoboken, NJ: John Wiley \& Sons.

Nordman, E. E. (2010). Wind Energy Glossary: Technical Terms and Concepts. Allendale, MI: Grand Valley State University.

North SEE (2016). Offshore Renewable Energy Developments - Offshore Wind [Online]. Available online at: https://northsearegion.eu/northsee/e-energy/ 
offshore-renewable-energy-developments-offshore-wind/ (accessed October 23, 2019).

Orr, A. J., Harris, J. D., Hirschberger, K. A., and DeLong, R. L. (2017). Qualitative and Quantitative Assessment of use of Offshore Oil and Gas Platforms by the California Sea Lion (Zalophus californianus). Technical report: U.S. Department of Commerce, NOAA Technical Memorandum NMFS-AFSC-362).

OSPAR (1998). "OSPAR decision $98 / 3$ on the disposal of disused offshore installations," in Proceedings of the OSPAR 98/14/1-E, Annex 33. Ministerial meeting of the Oslo and Paris Convention, OSPAR Convention for the Protection of the Marine Environment of the North-East Atlantic, Sintra.

OSPAR (2017). "2016 status report on the OSPAR network of marine protected areas," in Biodiversity and Ecosystems Series. Convention for the Protection of the Marine Environment of the North-East Atlantic, ed. J. Hennicke (Amsterdam: OSPAR).

Pace, D. S., Giacomini, G., Campana, I., Paraboschi, M., Pellegrino, G., Silvestri, M., et al. (2019). An integrated approach for cetacean knowledge and conservation in the central Mediterranean Sea using research and social media data sources. Aqua. Conserv. Mar. Freshw. Ecosyst. 29, 1302-1323. doi: 10.1002/aqc.3117

Pan, H., Yu, H., Ravi, V., Li, C., Lee, A. P., Lian, M. M., et al. (2016). The genome of the largest bony fish, ocean sunfish (Mola mola), provides insights into its fast growth rate. GigaScience 5:36.

Parente, V., Ferreira, D., Moutinho dos Santos, E., and Luczynski, E. (2006). Offshore decommissioning issues: deductibility and transferability. Energy Policy 34, 1992-2001. doi: 10.1016/j.enpol.2005.02.008

Parton, K. J., Galloway, T. S., and Godley, B. J. (2019). Global review of shark and ray entanglement in anthropogenic marine debris. Endang. Spec. Res. 39, 173-190. doi: 10.3354/esr00964

Piechaud, N., Hunt, C., Culverhouse, P. F., Foster, N. L., and Howell, K. L. (2019). Automated identification of benthic epifauna with computer vision. Mar. Ecol. Prog. Ser. 615, 15-30. doi: 10.3354/meps12925

Robinson, D. P., Jaidah, M. Y., Jabado, R. W., Lee-Brooks, K., Nour El-Din, N. M., Malki, A. A. A., et al. (2013). Whale Sharks, Rhincodon typus, aggregate around offshore platforms in Qatari waters of the Arabian Gulf to feed on fish spawn. PLoS One 8:e58255. doi: 10.1371/journal.pone.0058255

Rosman, I., Boland, G. S., Martin, L., and Chandler, C. (1987). Underwater Sightings of Sea Turtles in the Northern Gulf of Mexico. Houston, TX: U.S. Department of the Interior Minerals Management Service.

Russell, D. J. F., Brasseur, S. M. J. M., Thompson, D., Hastie, G. D., Janik, V. M., Aarts, G., et al. (2014). Marine mammals trace anthropogenic structures at sea. Curr. Biol. 24, R638-R639.

Sayer, M., Magill, S., Pitcher, T., Morissette, L., and Ainsworth, C. (2005). Simulation-based investigations of fishery changes as affected by the scale and design of artificial habitats. J. Fish Biol. 67(Suppl. B), 218-243. doi: 10.1111/j. 0022-1112.2005.00928.x

Schlumberger (2019). The Oilfield Glossary [Online]. Available online at: https://www.glossary.oilfield.slb.com/ (accessed July 04, 2019)

Shirihai, M., and Jarrett, B. (2006). Whales, Dolphins and Seals: A Field Guide to the Marine Mammals of the World. London: A\&C Black Publishers Ltd.

Sisneros, J. A., and Tricas, T. C. (2002). Neuroethology and life history adaptations of the elasmobranch electric sense. J. Physiol. Paris 96, 379-389. doi: 10.1016/ S0928-4257(03)00016-0

Sisneros, J. A., Tricas, T. C., and Luer, C. A. (1998). Response properties and biological function of the skate electrosensory system during ontogeny. J. Compar. Physiol. A 183, 87-99. doi: 10.1007/s0035 90050237

Soldal, A. V., Svellingen, I., Jørgensen, T., and Løkkeborg, S. (2002). Rigs-toreefs in the North Sea: hydroacoustic quantification of fish in the vicinity of a "semi-cold" platform. ICES J. Mar. Sci. 59, S281-S287.

Sward, D., Monk, J., and Barrett, N. (2019). A systematic review of remotely operated vehicle surveys for visually assessing fish assemblages. Front. Mar. Sci. 6:19. doi: 10.3389/fmars.2019.00134

Teilmann, J., Miller, L. A., Kirketerp, T., Kastelein, R. A., Madsen, P. T., Nielsen, B. K., et al. (2002). Characteristics of echolocation signals used by a harbour porpoise (Phocoena phocoena) in a target detection experiment. Aqua. Mamm. $28,275-284$.

Thompson, P. M., Lusseau, D., Barton, T., Simmons, D., Rusin, J., and Bailey, H. (2010). Assessing the responses of coastal cetaceans to the construction of offshore wind turbines. Mar. Pollut. Bull. 60, 1200-1208. doi: 10.1016/j. marpolbul.2010.03.030

Todd, V. L. G., Lavallin, E. W., and Macreadie, P. I. (2018). Quantitative analysis of fish and invertebrate assemblage dynamics in association with a North Sea oil and gas installation complex. Mar. Environ. Res. 142, 69-79. doi: 10.1016/j. marenvres.2018.09.018

Todd, V. L. G., Pearse, W. D., Tregenza, N. C., and Todd, I. B. (2009). Diel echolocation activity of harbour porpoises (Phocoena phocoena) around North Sea offshore gas installations. ICES J. Mar. Sci. 66, 734-745. doi: 10.1093/ icesjms/fsp035

Todd, V. L. G., Todd, I. B., Gardiner, J. C., and Morrin, E. C. N. (2015). Marine Mammal Observer and Passive Acoustic Monitoring Handbook. Exeter: Pelagic Publishing Ltd.

Todd, V. L. G., Warley, J. C., and Todd, I. B. (2016). Meals on wheels? A decade of megafaunal visual and real-time passive acoustic monitoring detections from on-tow and stationary offshore oil and gas rigs and platforms in the North and Irish Seas. PLoS One 11:25. doi: 10.1371/journal.pone.015 3320

Todd, V. L. G., Williamson, L. D., Cox, S. E., Todd, I. B., and Macreadie, P. I. (2019). Characterising the first wave of fish and invertebrate colonisation on a new offshore petroleum platform. ICES J. Mar. Sci. Fsz077. doi: 10.1093/ icesjms/fsz077

Topham, E., and McMillan, D. (2017). Sustainable decommissioning of an offshore wind farm. Renewable Energy 102, 470-480. doi: 10.1016/j.renene.2016.10.066

Tricas, T. C., Michael, S. W., and Sisneros, J. A. (1995). Electrosensory optimisation to conspecific phasic signals for mating. Neurosci. Lett. 202, 129-132. doi: 10.1016/0304-3940(95)12230-3

Triossi, F., Willis, T. J., and Pace, D. S. (2013). Occurrence of bottlenose dolphins Tursiops truncatus in natural gas fields of the northwestern Adriatic Sea. Mar. Ecol. 34, 373-379. doi: 10.1111/maec.12020

Twomey, B. (2012). "Artificial reefs," in Proceedings of the Workshop on End of Concession and Decommissioning, (Bangkok: CCOP).

UK National Data Repository (2019). Available online at: https://ndr.ogauthority. co.uk/dp/pages/apptab/ITabManager.jsp (accessed June 13, 2019).

UK Public General Acts (1987). Petroleum Act 1987. London: UK Public General Acts.

Urick, R. J. (1983). Principles of Underwater Sound, 3rd Edn. New York, NY: McGraw-Hill.

van der Molen, J., García-García, L. M., Whomersley, P., Callaway, A., Posen, P. E., and Hyder, K. (2018). Connectivity of larval stages of sedentary marine communities between hard substrates and offshore structures in the North Sea. Sci. Rep. 8:14772.

van Elden, S., Meeuwig, J. J., Hobbs, R. J., and Hemmi, J. M. (2019). Offshore oil and gas platforms as novel ecosystems: a global perspective. Front. Mar. Sci. 6:548. doi: $10.3389 /$ fmars. 2019.00548

Villadsgaard, A., Wahlberg, M., and Tougaard, J. (2007). Echolocation signals of wild harbour porpoises, Phocoena phocoena. J. Exp. Biol. 210, 56-64. doi: 10.1242/jeb.02618

Walker, M. M., Kirschvink, J. L., Ahmed, G., and Dizon, A. E. (1992). Evidence that fin whales respond to the geomagnetic field during migration. J. Exp. Biol. 171, 67-78.

Watkins, W. A., Daher, M. A., Fristrup, K. M., Howald, T. J., and Disciara, G. N. (1993). Sperm whales tagged with transponders and tracked underwater by sonar. Mar. Mamm. Sci. 9, 55-67. doi: 10.1111/j.1748-7692.1993.tb00426.x

Watwood, S. L., Miller, P. J. O., Johnson, M., Madsen, P. T., and Tyack, P. L. (2006). Deep-diving foraging behaviour of sperm whales (Physeter macrocephalus). J. Anim. Ecol. 75, 814-825. doi: 10.1111/j.1365-2656.2006. 01101.x

Wauters, L., Swinnen, C., and Dhondt, A. (1992). Activity budget and foraging behaviour of red squirrels (Sciurus vulgaris) in coniferous and deciduous habitats. J. Zool. 227, 71-86. doi: 10.1111/j.1469-7998.1992.tb0 4345.x

Whitehead, H. (2018). "Sperm whale: Physeter macrocephalus," in Encyclopedia of Marine Mammals, eds W. Perrin, B. Wursig, and J. G. M. Thewissen (San Francisco, CA: Elsevier), 919-925.

Wind Energy Association (2020). Glossary. Available online at: https://www.windenergy-the-facts.org/glossary.html (accessed June 4, 2020). 
Wood, G. (1983). The Guinness Book of Animal Facts and Feats. New York, NY: Sterling Publishing.

Yurk, H., and Trites, A. W. (2000). Experimental attempts to reduce predation by harbor seals on out-migrating juvenile salmonids. Trans. Am. Fish. Soc. 129, 1360-1366. doi: 10.1577/1548-8659(2000)129<1360:eatrpb $>$ 2.0.co;2

Zawawi, N. A. W. A., Liew, M. S., and Na, K. L. (2012). "Decommissioning of offshore platform: a sustainable framework," in Proceedings of the 2012 IEEE Colloquium on Humanities, Science and Engineering (CHUSER), (Kota Kinabalu: Institute of Electrical and Electronics Engineers (IEEE))

Zhou, L., and Gui, J.-F. (2010). Molecular mechanisms underlying sex change in hermaphroditic groupers. Fish Physiol. Biochem. 36, 181-193. doi: 10.1007/ s10695-008-9219-0
Conflict of Interest: VT, LL, LW, IP, AH, SC, and IT were employed by Ocean Science Consulting Limited.

The remaining authors declare that the research was conducted in the absence of any commercial or financial relationships that could be construed as a potential conflict of interest.

Copyright (C) 2020 Todd, Lazar, Williamson, Peters, Hoover, Cox, Todd, Macreadie and McLean. This is an open-access article distributed under the terms of the Creative Commons Attribution License (CC BY). The use, distribution or reproduction in other forums is permitted, provided the original author(s) and the copyright owner(s) are credited and that the original publication in this journal is cited, in accordance with accepted academic practice. No use, distribution or reproduction is permitted which does not comply with these terms. 